Citation: R. Portugal, I. Aguaded (2021) Representación de mujeres en noticias sobre violencia de género difundidas por televisión en Bolivia frente a las competencias mediáticas. Media Education 12(1): 115-123. doi: 10.36253/ me-10249

Received: December, 2020

Accepted: April, 2021

Published: May, 2021

Copyright: (c) 2021 R. Portugal, I. Aguaded. This is an open access, peerreviewed article published by Firenze University Press (http://www.fupress. $\mathrm{com} / \mathrm{me}$ ) and distributed under the terms of the Creative Commons Attribution License, which permits unrestricted use, distribution, and reproduction in any medium, provided the original author and source are credited.

Data Availability Statement: All relevant data are within the paper and its Supporting Information files.

Competing Interests: The Author(s) declare(s) no conflict of interest.

\section{Representación de mujeres en noticias sobre violencia de género difundidas por televisión en Bolivia frente a las competencias mediáticas}

\author{
Representation of women in news about gender violence \\ broadcast on television in Bolivia versus media literacy \\ Rigliana Portugal ${ }^{1}$, Ignacio Aguaded ${ }^{2}$ \\ 1 Facultad de Ciencias Sociales, Universidad Mayor de San Andrés. La Paz, Bolivia. \\ ORCID: https://orcid.org/0000-0002-4174-2911 \\ 2 Universidad de Huelva, España. ORCID: https://orcid.org/0000-0002-0229-1118 \\ E-mail: rigliana@gmail.com; aguaded@uhu.es
}

\begin{abstract}
The study analyzes the news content of three national television channels in Bolivia (one public and two private), where the treatment of news on gender violence is observed. The methodology proposed by Monitoreo Global de Medios, which addresses gender and media issues, is applied. At the same time, the dimensions of media literacy proposed by Ferrés and Piscitelli (2012) are analyzed in university women who observed the news broadcast on television. The findings show that there are more women $(59.05 \%)$ than men $(40.95 \%)$ as protagonists of the articles on gender violence, and that sexist stereotypes are reinforced in the presentation of the news. After applying the questionnaire to 200 university women, the technology dimension reached an advanced level (46.7\%) based on knowledge of technological concepts and image processing software. However, the dimension of interaction processes has a high percentage of $59.5 \%$ at the basic level, as there is a lack of knowledge of the possibilities of acting critically in the face of violent content presented in the media.
\end{abstract}

Keywords: news, violence, gender, Bolivia, media literacy.

Resumen. El estudio analiza contenidos informativos de tres canales de televisión de alcance nacional en Bolivia (uno público y dos privados), donde se observa el tratamiento de noticias sobre violencia de género. Se aplica la metodología propuesta por Monitoreo Global de Medios, que aborda temas de género y medios de comunicación. Paralelamente, se analizan las dimensiones de competencia mediática propuestas por Ferrés y Piscitelli (2012) en mujeres universitarias que observaron las noticias difundidas por televisión. Los hallazgos permiten observar que es mayor $(59,05 \%)$ la presencia de mujeres como protagonistas de las notas sobre violencia de género, respecto a los hombres (40,95\%), y por otro lado en la presentación de noticias se refuerzan los estereotipos sexistas. Tras la aplicación del cuestionario a 200 mujeres universitarias, la dimensión de tecnología alcanza un nivel avanzado $(46,7 \%)$ a partir del conocimiento de conceptos tecnológicos y de spara tratamiento de imágenes. Sin embargo, la dimensión de procesos de interacción tiene en el nivel básico el porcentaje alto de 59,5\%, pues se desconocen posibilidades de actuar de forma crítica ante contenido violento presentado en los medios.

Palabras clave: noticias, violencia, género, Bolivia, competencia mediática. 


\section{INTRODUCCIÓN}

El propósito de la investigación es determinar la representación de mujeres en las noticias sobre violencia de género que se difunden a través de canales de televisión de alcance nacional en Bolivia, considerando los roles que se les otorga y la presencia de estereotipos sexistas; así como caracterizar en mujeres universitarias que observaron los contenidos informativos, la presencia de dimensiones de la competencia mediática propuestas por Ferrés y Piscitelli (2012). En ese sentido, el problema de investigación establece: ¿cuál es la representación de las mujeres, en las noticias sobre violencia de género difundidas del 13 al 17 de julio de 2020, a través de los canales de televisión Red Unitel, Red UNO y Bolivia TV; y cuál es el nivel de competencia mediática de mujeres estudiantes de la Carrera de Ciencias de la Comunicación Social de la Universidad Mayor de San Andrés que observaron dichos contenidos noticiosos?

El objetivo general establece el determinar la representación de las mujeres en las noticias sobre violencia de género difundidas, a través de dos canales privados (Red Unitel y Red UNO) y uno público (Bolivia TV) de alcance nacional; precisando a su vez el nivel de competencia mediática de mujeres estudiantes de la Carrera de Ciencias de la Comunicación Social de la Universidad Mayor de San Andrés que observaron dichas informaciones.

En Bolivia, la violencia contra las mujeres está por encima del promedio latinoamericano, "el país ocupa el primer lugar en Sudamérica en feminicidios" (La Razón, 2019). En contexto de pandemia por COVID-19 se muestra desde marzo de 2020, un ascenso de casos de violencia ejercida contra las mujeres. El Observatorio de Género de la Coordinadora de la Mujer en Bolivia (2020) establece que "en 71 días de cuarentena rígida por la pandemia, se registran 2.935 denuncias por delitos contra la Ley $\mathrm{N}^{\circ} 348$, Ley para Garantizar a las Mujeres una Vida Libre de Violencia; de ellas, el 81\% corresponde a violencia en la familia" (Coordinadora de la Mujer, 2020).

La violencia está presente en todos los aspectos de la vida cotidiana y expresa relaciones de poder y de desigualdad entre hombres y mujeres. La violencia de género es el resultado de la cultura dominante patriarcal que va reproduciendo valores, así como creencias, tradiciones, prejuicios, costumbres consideradas superiores. Por ello, tiene como raíz las relaciones desiguales de poder, pero sobre todo es estructural, porque la organización social es patriarcal (Lagarde, 2011; Vega, 2014).

La violencia es uno de los problemas más complejos que enfrenta la sociedad y que ha incidido en la palestra internacional. La Declaración Universal de los Derechos Humanos de 1948, así como la Convención para la Eli- minación de todas las formas de Discriminación contra la Mujer (CEDAW) de 1981, constituyen referentes clave para analizar la violencia de género. La CEDAW ante la brecha de acceso y ejercicio de derechos por mujeres y hombres, establece medidas hacia la igualdad de género y ejercicio efectivo de derechos de las mujeres. En 1994 la Convención Interamericana para Prevenir, Sancionar y Erradicar la Violencia contra la Mujer (Belém do Pará) aportó desde el nivel conceptual la comprensión de la violencia contra la mujer como cualquier acción o conducta, basada en género, que causa muerte, daño o sufrimiento físico, sexual o psicológico, tanto en el ámbito público o privado (Ministerio de Desarrollo Social, 2012).

A su vez, ya ingresando al terreno mediático, en 1995 la Cuarta Conferencia Mundial sobre la Mujer en Beijing en el apartado J relativo a la mujer y los medios de difusión, precisó que aunque se ha incrementado el número de mujeres que hacen carrera en el sector de las comunicaciones, pocas ocupan cargos directivos que inciden en la política de los medios; por otro lado el tema de género es desatendido en los medios de información donde persisten estereotipos basados en género (Informe de la Cuarta Conferencia Mundial sobre la Mujer, 1995; Chaher, 2010).

A nivel investigativo, los estudios sobre violencia de género son diversos y amplios. Destacan aportes desde los feminismos decoloniales con perspectiva de interseccionalidad con Lugones (2007); pasando por contribuciones de Segato (2011) desde la perspectiva teórica de la colonialidad del poder donde las relaciones de género capturan formas de patriarcado y donde la violencia es ejercida con letalidad. De igual modo, Espinosa, Gómez, Lugones, y Ochoa (2013), efectúan estudios referidos al dominio sobre la vida de mujeres que tiene una historia de racialización íntimamente ligada a una visión moderna de la humanidad, donde el ejercicio de la violencia es una constante en contra de las mujeres por el hecho de ser tales.

Existen trabajos que analizan la violencia ejercida desde los medios de comunicación en contra de las mujeres. Un estudio de Cynthia Pech (2013) explica que a nivel de las investigaciones en el campo de la comunicación, se ha evidenciado la "invisibilidad de las mujeres" en los medios de comunicación, donde la cultura del audiovisual ha construido la imagen de la mujer desde los estereotipos, explicitando "relaciones sociales asimétricas" (Cruz, 2013, p. 281). Para Pech la violencia de género que los medios de comunicación representan y reproducen es una violencia simbólica, empleada como mecanismo de educación de las personas. De hecho, el sistema de violencia simbólica legitima y perpetúa la violencia de dominantes sobre dominados (Sentamans, 2012). 
Afirma Vega (2014) que los medios de comunicación no visibilizan a las mujeres como agentes sociales capaces de influir en ámbitos políticos, económicos, sociales, educativos y culturales, sino por el contrario son representadas, en el discurso mediático (tradicional y de las tecnologías) desde la reproducción de estereotipos sexistas, vinculadas con los roles tradicionales de lo doméstico y sumiso. "Los medios de comunicación no sólo no promueven los derechos humanos de las mujeres, sino que lucran con la posibilidad de reproducir la violencia de género" (Vega, 2014, p. 16), pese a que "tienen la responsabilidad de erradicar la violencia contra las mujeres" (Vega, 2010, p. 53).

Un estudio realizado por Inostroza (2009) referido a relatos de violencia en televisión en Chile, precisó que persisten los elementos que normalizan, naturalizan, invisibilizan y reproducen la violencia contra las mujeres. Los presentadores de televisión a través de su relato, enfatizan en frases cargadas de sensacionalismo: "dramática madrugada", "una noche de horror", "tremenda tragedia”. De esta forma la violencia contra las mujeres se espectaculariza, desde noticieros, talk shows y series. Bolla y Gómez (2017) explican que en el discurso de los medios de comunicación, las mujeres son víctimas en el sentido más tradicional: no sujetos sino cuasi-objetos a quienes les suceden cosas porque son responsables de ello. En esa misma línea afirma Valdez (2020) que el "sensacionalismo en las pantallas con mujeres asesinadas o violentadas y mostradas espectacularmente de forma repetitiva hace que las audiencias consideren estas vulneraciones como una anécdota más" (p. 87).

Desde un enfoque antipatriarcal Galindo (2020) considera que los medios se constituyen en estructuras de réplica de poder, que abordan temas como el género desde un ámbito periférico, subalterno y no de análisis central. Por ello es central profundizar en diagnósticos que identifiquen cómo se aborda la violencia en los medios desde las informaciones, las fuentes que se emplean, el lenguaje que se utiliza, hasta la domesticación del feminismo y la tecnocracia de género.

Por otro lado, frente al contenido violento difundido por los medios de información, se encuentran las competencias mediáticas capaces de promover el desarrollo de conocimientos, habilidades y actitudes para hacer frente a mensajes con carga violenta. El origen de la competencia mediática proviene de la necesidad de educar para los medios a nivel escolar (Gutiérrez y Tyner, 2012); su tendencia establece la determinación del contexto digital y el desarrollo de aptitudes orientadas hacia la educación de los medios, y las tecnologías de la información y de la comunicación (Luke, 2007, Lee et al., 2013). Se considera como un proceso de aprendi- zaje dinámico, no lineal, de habilidades interpretativas hacia nuevos medios (Livingstone, 2004). La competencia requiere para su implementación del soporte institucional y el apoyo de educadores (Hobbs, 1998; Livingstone, 2004); por cuanto ofrece herramientas para desarrollar el pensamiento crítico sobre el rol de las comunicaciones comerciales, fomentando la educación democrática (Hobbs, 1998; Koltay, 2011; Romero-Rodríguez, Torres-Toukoumidis, Pérez-Rodríguez \& Aguaded, 2016, pp. 15-16). Investigadores como Fedorov y Levitskaya (2015) precisan que "la competencia mediática es un concepto multidimensional" (p. 108) que implica el desarrollo de "habilidades para la recepción, la decodificación, la creación y el análisis crítico, ante el exceso de información que no beneficia al conocimiento" (Pérez-Rodríguez, Delgado-Ponce, García-Ruiz \& Caldeiro, 2015, p. 19). Este estudio aborda la competencia mediática como el "dominio de conocimientos, destrezas y actitudes relacionados con seis dimensiones básicas, de las que se ofrecen los indicadores principales" (Ferrés \& Piscitelli, 2021, p. 79).

Por lo expuesto las hipótesis establecidas son: La representación de las mujeres, dentro las noticias sobre violencia de género, difundidas del 13 al 17 de julio de 2020, a través de los canales de televisión Red Unitel, Red UNO y Bolivia TV, destaca estereotipos sexistas y roles de género reproductivos que contribuyen en la invisibilización de la violencia de género. Es limitado el nivel de competencia mediática de mujeres estudiantes de la Carrera de Ciencias de la Comunicación Social de la Universidad Mayor de San Andrés ante las noticias sobre violencia de género.

\section{MÉTODO}

El proyecto de Monitoreo Global de Medios es una iniciativa de investigación e incidencia en temas de género y medios de comunicación de la Asociación Mundial para la Comunicación Cristiana. La metodología permitió una aproximación al estudio de las noticias difundidas en tres noticieros emitidos en La Paz, Bolivia entre el 13 al 17 de julio de 2020, en las redes televisivas privada Unitel y Red UNO, y pública Bolivia TV. El espacio analizado fue el de los noticieros centrales presentados en horario nocturno. Los tópicos de estudio abordan: a) Presencia de mujeres y hombres en las noticias de televisión; b) Contenido de las noticias televisivas; c) Segmento de horarios y programas donde se presenta contenido violento; d) Mujeres como fuente y protagonistas de la información; e) Espectacularización del hecho noticioso; f) Mujeres como "víctimas"; g) Rol de presentadoras 
y conductores; h) Casting y vestimenta; i) Roles masculinos y femeninos; j) Estereotipos sexistas; k) Lenguaje sexista. La herramienta validada por expertos fue aplicada para el análisis, según el lapso señalado.

A su vez, las dimensiones de la competencia mediática se abordaron a través de la aplicación de un cuestionario que consideró las dimensiones descritas por Ferrés \& Piscitelli (2012), expresadas en 23 preguntas (con una condicionada 19.1) que agrupaban las 6 dimensiones ordenadas por indicadores (Tabla 1). Las cuatro primeras preguntas $(1,2,3$ y 4$)$ permitían construir el perfil de 200 estudiantes mujeres de la Carrera de Ciencias de la Comunicación Social de la Universidad Mayor de San Andrés. Los indicadores se relacionaron con el ámbito de análisis referido a la participación como "personas que reciben mensajes e interaccionan con ellos" (ámbito de análisis) y como personas que "producen mensajes" (ámbito de la expresión). La puntuación máxima del cuestionario alcanzó los 51 puntos (100\%) (Tabla 2). Los resultados se agruparon en 3 niveles que se corresponden con Básico, Medio y Avanzado (Tabla 3).

\section{RESULTADOS}

A través de la metodología del Monitoreo Global de Medios se abordaron 17 noticias sobre violencia de género en Unitel, 10 en Bolivia TV y 22 en la Red Uno;

Tabla 1. Relación de dimensiones, indicadores y número de preguntas asociadas a la dimensión de la competencia mediática.

\begin{tabular}{|c|c|c|c|}
\hline \multirow{2}{*}{ Dimensión } & \multicolumn{2}{|c|}{ Indicadores } & \multirow{2}{*}{$\begin{array}{l}\text { Número de } \\
\text { preguntas por } \\
\text { dimensión }\end{array}$} \\
\hline & Ámbito de análisis & Ámbito de expresión & \\
\hline Lenguaje & $\begin{array}{l}\text { Capacidad de: interpretar y valorar diversos códigos; } \\
\text { análisis y valoración de mensajes desde el significado } \\
\text { y sentido, estructuras narrativas, convenciones } \\
\text { de género y formato; comprensión de historias; } \\
\text { establecimiento de relaciones entre textos, códigos, } \\
\text { medios, elaborando conocimientos. }\end{array}$ & $\begin{array}{l}\text { Capacidad de: expresarse mediante sistemas de } \\
\text { representación y significación; elección entre distintos } \\
\text { sistemas de representación y estilos en función } \\
\text { de la situación comunicativa, tipo de contenido a } \\
\text { transmitir, de interlocutor; modificar productos } \\
\text { existentes dándoles nuevo sentido y valor. }\end{array}$ & $\begin{array}{l}\text { Tres preguntas: } 7 \text {, } \\
10 \text { y } 11\end{array}$ \\
\hline Tecnología & $\begin{array}{l}\text { Comprensión del papel que desempeñan en la } \\
\text { sociedad las tecnologías de la información y de } \\
\text { la comunicación y de sus efectos; habilidad para } \\
\text { interactuar significativamente con medios que } \\
\text { permiten expandir capacidades mentales; utilización } \\
\text { de las innovaciones tecnológicas (comunicación } \\
\text { multimodal y multimedial); capacidad de } \\
\text { desenvolverse con eficacia en entornos hipermediales, } \\
\text { transmediáticos y multimodales. }\end{array}$ & $\begin{array}{l}\text { Manejo con corrección de herramientas } \\
\text { comunicativas en un entorno multimedial y } \\
\text { multimodal; adecuación de herramientas tecnológicas } \\
\text { a los objetivos comunicativos que se persiguen; } \\
\text { elaboración y manipulación de imágenes y sonidos } \\
\text { desde la conciencia de cómo se construyen las } \\
\text { representaciones de la realidad. }\end{array}$ & $\begin{array}{c}\text { Tres preguntas: } 13 \text {, } \\
14 \text { y } 20\end{array}$ \\
\hline $\begin{array}{l}\text { Procesos de } \\
\text { interacción }\end{array}$ & $\begin{array}{l}\text { Capacidad de selección, revisión y autoevaluación de } \\
\text { la dieta mediática; reconocimiento de por qué gustan } \\
\text { unos medios, productos o contenidos, por qué tienen } \\
\text { éxito, individual o colectivamente: qué necesidades y } \\
\text { deseos satisfacen en lo sensorial, emotivo, cognitivo, } \\
\text { estético, cultural, etc.; valoración de los efectos } \\
\text { cognitivos de las emociones: tomar conciencia de las } \\
\text { ideas y valores que se asocian con personajes, acciones } \\
\text { y situaciones que generan, según los casos, emociones } \\
\text { positivas y negativas; diferenciación y gestión de } \\
\text { las disociaciones que se producen a veces entre } \\
\text { sensación y opinión, entre emotividad y racionalidad; } \\
\text { conocimiento de la importancia del contexto en } \\
\text { los procesos de interacción; conocimientos sobre } \\
\text { el concepto de audiencia, sobre los estudios de } \\
\text { audiencia, su utilidad y sus límites; capacidad de } \\
\text { apreciar los mensajes provenientes de otras culturas } \\
\text { para el diálogo intercultural en un período de medios } \\
\text { transfronterizos; gestión del ocio mediático como } \\
\text { oportunidad para el aprendizaje. }\end{array}$ & $\begin{array}{l}\text { Actitud activa en la interacción con las pantallas, } \\
\text { oportunidad para construir una ciudadanía más } \\
\text { plena, un desarrollo integral, para transformarse y } \\
\text { para transformar el entorno; trabajo colaborativo } \\
\text { mediante la conectividad y la creación de plataformas } \\
\text { que facilitan las redes sociales; interacción con } \\
\text { personas y diversos colectivos en contextos plurales } \\
\text { y multiculturales; conocimiento de las posibilidades } \\
\text { legales de reclamo ante el incumplimiento de las } \\
\text { normas vigentes en materia audiovisual, y actitud } \\
\text { responsable ante estas situaciones; reconocimiento } \\
\text { de un programa apto para mayores o menores de } \\
\text { edad; reconocimiento de la necesidad de realizar el } \\
\text { control del tiempo que se dedica a los medios y las } \\
\text { tecnologías; reconocimiento de las emociones ante } \\
\text { un producto mediático; denuncia o queja debido a } \\
\text { las imágenes expuestas; participación activa, a través } \\
\text { de las tecnologías y los medios, en temas que orden } \\
\text { social, político, económico, cultural, etc; permite } \\
\text { plantearse si es uno quien decide lo que ve por } \\
\text { televisión. }\end{array}$ & $\begin{array}{c}\text { Cuatro preguntas: } \\
12,16,19 \text { y } 19.1\end{array}$ \\
\hline
\end{tabular}




\begin{tabular}{llll}
\hline \multirow{2}{*}{ Dimensión } & Indicadores & & Número de \\
\cline { 2 - 3 } & Ámbito de análisis & Ámbito de expresión & $\begin{array}{c}\text { preguntas por } \\
\text { dimensión }\end{array}$ \\
\hline
\end{tabular}

Conocimiento de las fases, de los procesos de producción y de la infraestructura necesaria Conocimiento de las diferencias básicas entre lo que para producciones de carácter personal, grupal o son producciones individuales y colectivas, popular corporativo; trabajo colaborativo en la elaboración de y corporativas; conocimiento de los factores que productos multimedia o multimodales; selección de convierten las producciones corporativas en mensajes mensajes significativos, apropiación y transformación sometidos a los condicionamientos socioeconómicos de ellos para producción de nuevos significados; Procesos de de toda industria; conocimientos básicos sobre los capacidad de compartir y diseminar información con producción sistemas de producción, las técnicas de programación medios tradicionales y redes sociales, incrementando y difusión y los mecanismos de difusión; conocimiento de los códigos de regulación y de autorregulación que amparan, protegen y exigen a los distintos actores sociales, y de los colectivos y asociaciones que velan por su cumplimiento, y actitud activa y responsable ante ellos.

la visibilidad de mensajes, en interacción con amplias

Tres preguntas: 18 , 21 y 22 comunidades; utilización de la propia identidad online/offline y actitud responsable ante el control de datos privados, propios, ajenos; gestión del concepto de autoría; generación redes de colaboración y retroalimentación, y actitud comprometida ante ellas; producción y difusión; capacidad para gestionar la visibilidad de forma responsable.

Manera en que las representaciones mediáticas estructuran nuestra percepción de la realidad; evaluación de la fiabilidad de las fuentes de información, extrayendo conclusiones tanto de lo que se dice como de lo que se omite; búsqueda, organización, contraste, priorización y síntesis de informaciones procedentes de distintos sistemas y de diferentes entornos; detección de intenciones o intereses tanto en las producciones corporativas com en las populares, su ideología y valores, explícitos o latentes, adoptando una actitud crítica ante ellos; actitud ética a la hora de descargar productos útiles

Ideología y para la consulta, la documentación o el visionado valores de entretenimiento; análisis de las identidades virtuales e individuales y colectivas, y detección de los por estereotipos (género, raza, etnia, clase social, religión, cultura, discapacidades) causas y consecuencias; análisis crítico de los efectos de creación de opinión y reconocimiento de los procesos de identificación emocional con los personajes y las situaciones de las historias como mecanismo de manipulación o para conocernos mejor a nosotros mismos y para abrirnos a otras experiencias; gestión de propias emociones en la interacción con las pantallas, en función de la ideología y de los valores que se transmiten en ellas.

Reconocimiento de los aspectos formales, no sólo de lo que se comunica sino también de la manera cómo se comunica; sensibilidad para reconocer una producción mediática que no se adecue a unas Estética exigencias mínimas de calidad estética; relación de la producciones mediáticas con otras manifestaciones artísticas, detectando influencias mutuas; identificación de las categorías estéticas básicas, como la innovación formal y temática, la originalidad, el estilo, las escuelas y tendencias.
Aprovechamiento de las nuevas herramientas comunicativas para transmitir valores y para contribuir a la mejora del entorno, desde una de productos y de modificación de los existentes para cuestionar valores o estereotipos presentes en algunas producciones mediáticas; aprovechamiento o de las herramientas del nuevo entorno comunicativo para el compromiso con la ciudadanía responsable en la cultura y en la sociedad; la competencia mediática es posible de ser observada si se decide comprar un producto, por decisión propia, por estar convencido y no porque una persona se deje llevar por las emociones que son generadas a través de la música, los colores, los personales, los sonidos; la persona pueda aproximarse a determinar si es capaz de percibir mensajes entre líneas, o informaciones sesgadas, ante las noticias de televisión, prensa, etc. posicionando y manteniendo una opinión propia; se reconoce la imagen estereotipada de la mujer en la publicidad, o el tratamiento racista en determinadas informaciones periodísticas, o visiones homogéneas de una cultura dominante, o el posicionamiento de informaciones en redes sociales, o fake news.

Producción de mensajes que sean comprensibles y que contribuyan a incrementar los niveles personales o colectivos de creatividad, originalidad y sensibilidad; apropiación y transformación de producciones artísticas, potenciando la creatividad, innovación, experimentación y sensibilidad artística; observación de la composición de los elementos, los efectos, colores, planos, ángulos, contexto, etc.; aprecia el valor estético en las producciones: música, escultura, pintura, etc. que emplean referentes culturales que están en los medios masivos. actitud de compromiso social y cultural; elaboración
Tres preguntas: 6 , 15 y 17
Tres preguntas: 5 , 8 y 9

Fuente. Muestra las dimensiones de competencia mediática propuesta por Joan Ferrés \& Alejandro Piscitelli. Adaptado de "La competencia mediática: propuesta articulada de dimensiones e indicadores", por J. Ferrés \& A. Piscitelli, 2012, Comunicar 19(38) p. 75-82. Copyright 2012 por Revista Comunicar. 
Tabla 2. Relación de dimensiones con puntaje asignado.

\begin{tabular}{lc}
\hline Dimensión & Puntaje \\
\hline Lenguaje & 7 \\
Tecnología & 8 \\
Procesos de interacción & 9 \\
Procesos de producción y difusión & 9 \\
Ideología y valores & 9 \\
Estética & 9 \\
Total & 51
\end{tabular}

Fuente: Elaboración propia.

Tabla 3. Relación entre niveles y puntaje asignado.

\begin{tabular}{lc}
\hline Dimensión & Puntaje \\
\hline Básico & $0-23$ \\
Medio & $24-40$ \\
Avanzado & $41-51$ \\
\hline
\end{tabular}

Fuente: Elaboración propia.

haciendo un total de 49 noticias. Del total, el 7\% eran informaciones referidas a violencia laboral contra mujeres, $10 \%$ eran noticias sobre robos y atracos con afectación a mujeres, $10 \%$ sobre abusos a menores de edad (más de la mitad las afectadas eran niñas), 10\% sobre violencia psicológica, $15 \%$ violencia física contra mujeres, $20 \%$ violencia sexual y $28 \%$ informaciones referidas a feminicidios.

A nivel de la representación de mujeres y hombres en las noticias, destaca mayor presencia de mujeres como presentadoras de informaciones referidas a hechos de violencia. Son mujeres periodistas (reporteras) las que en su mayoría dan cuenta de informaciones sobre violen- cia de género (57,45\%), mientras que los varones alcanzan el $42,55 \%$. Las presentadoras anticipan la emisión de la noticia y la transición de cierre señalando: "en otra información”, “otra víctima más”, frases que invisibilizan la violencia de género. Los protagonistas de las notas informativas sobre violencia de género son en un 59,05\% mujeres, frente a un 40,95\% que son varones (Tabla 4).

El manejo de fuentes de información en general es de carácter oficial y corresponden en su mayoría a instancias de gobierno: Policía, Fiscalía, Fuerza Especial de Lucha contra el Crimen, Servicio Legal Integral Municipal. Todas las fuentes masculinas utilizadas presentan datos completos de nombre y cargo, sin embargo las fuentes femeninas sólo en un 70\% presentan datos completos, siendo el 30\% incompletos. A las mujeres que no tienen datos, se las presenta en tanto "esposa de", "hija de", "hermana de". El 66\% de las fuentes consultadas son masculinas y $34 \%$ femeninas.

El total de las noticias presentan como protagonista de los hechos de violencia a las mujeres, quienes reciben el apelativo de "víctimas". A través de imágenes, música y sonidos se refuerza el rol de mujer débil y sumisa. Las informaciones sobre violencia de género presentadas por los medios, en el lapso estudiado, no vincularon ninguno de los hechos con vulneración de derechos humanos, tampoco apelaron a la prevención.

A nivel del análisis de lenguaje en los medios privados, destaca el morbo al conocer "detalles" de un acto de violencia sexual y física. Se apela a la narración para presentar los hechos, apelando a estereotipos negativos, sexistas, discriminatorios donde se subalterniza a la mujer, destacando su rol reproductivo como madre, esposa o hija. La inclusión de palabras como: "la destrozó", "estranguló"; y el uso de adjetivos como "macabro", "horrendo", no abordan un enfoque de género, ni de derechos.

Tabla 4. Género en las redes televisivas del 13 al 17 de julio de 2020.

\begin{tabular}{|c|c|c|c|c|c|c|c|c|}
\hline Red televisiva & \multicolumn{2}{|c|}{ Unitel } & \multicolumn{2}{|c|}{ Bolivia $\mathrm{Tv}$} & \multicolumn{2}{|c|}{ Red Uno } & \multicolumn{2}{|c|}{ Total } \\
\hline Notas analizadas & \multicolumn{2}{|c|}{17} & \multicolumn{2}{|c|}{10} & \multicolumn{2}{|c|}{22} & \multicolumn{2}{|c|}{49} \\
\hline Género de los periodistas y presentadores & Cantidad & Porcentaje & Cantidad & Porcentaje & Cantidad & Porcentaje & Cantidad & Porcentaje \\
\hline Hombres & 9 & $33.33 \%$ & 9 & $56.25 \%$ & 22 & $43.14 \%$ & 40 & $42.55 \%$ \\
\hline Mujeres & 18 & $66.67 \%$ & 7 & $43.75 \%$ & 29 & $56.86 \%$ & 54 & $57.45 \%$ \\
\hline Género de los protagonistas de las noticias & Cantidad & Porcentaje & Cantidad & Porcentaje & Cantidad & Porcentaje & Cantidad & Porcentaje \\
\hline Hombres & 31 & $42.47 \%$ & 14 & $37.84 \%$ & 41 & $41.00 \%$ & 86 & $40.95 \%$ \\
\hline Mujeres & 42 & $57.53 \%$ & 23 & $62.16 \%$ & 59 & $59.00 \%$ & 124 & $59.05 \%$ \\
\hline
\end{tabular}

Fuente: Información acumulativa de participaciones dentro del periodo de análisis (del 13 al 17 de julio). Elaboración propia. 
Tabla 5. Relación entre dimensiones y nivel alcanzado por las mujeres.

\begin{tabular}{lcccccc}
\hline & Lenguaje & $\begin{array}{c}\text { Tec- } \\
\text { nología }\end{array}$ & $\begin{array}{c}\text { Procesos } \\
\text { de Inter- } \\
\text { acción }\end{array}$ & $\begin{array}{c}\text { Procesos } \\
\text { de pro- Ideología } \\
\text { ducción y y Valores } \\
\text { difusión }\end{array}$ \\
\hline Avanzadótica \\
Medio & $24,4 \%$ & $46,7 \%$ & $10,3 \%$ & $7,0 \%$ & $14,3 \%$ & $7,0 \%$ \\
Básico & $36,6 \%$ & $22,0 \%$ & $30,2 \%$ & $15,0 \%$ & $19,7 \%$ & $28,0 \%$ \\
\hline
\end{tabular}

Fuente: Elaboración propia.

En cuanto a las competencias mediáticas de las estudiantes de la Carrera de Ciencias de la Comunicación de la Universidad Mayor de San Andrés, destaca el nivel avanzado en la dimensión de Tecnología (46,7\%) expresado en el conocimiento de conceptos vinculados a esa área. Sin embargo, la dimensión del Lenguaje presenta un nivel básico $(24,4 \%)$ por cuanto existen dificultades en la identificación del significado de contenidos verbales o icónicos. En la dimensión de Procesos de Interacción, el nivel de las estudiantes es básico (59,5\%) y demanda un trabajo para el desarrollo de conocimientos básicos sobre audiencia y estudios vinculados a ella. La dimensión de Procesos de Producción y Difusión es básica $(78,0 \%)$ pues se desconoce el manejo de riesgos asociados a la gestión de la identidad on-line. En la dimensión de Ideología y Valores el nivel también es básico $(66,05 \%)$ e implica la limitada capacidad para reconocer los estereotipos de género presentes en contenidos audiovisuales. La dimensión Estética es principalmente básica (65\%) y muestra la importancia de trabajar en el fortalecimiento de capacidades para el reconocimiento de los elementos como imágenes, textos y música que se conjugan en contenidos referidos a violencia (Tabla 5).

\section{DISCUSIÓN}

El estudio evidencia la estructura patriarcal y de poder que subalterniza a la mujer en los medios de comunicación, independientemente de las funciones que desempeñe, sea como presentadora o como periodista. Ella es parte del engranaje de funcionamiento del medio que otorga espectacularidad al hecho noticioso, con especial interés al contenido violento. Se requiere profundizar en el estudio sobre el rol de las presentadoras y periodistas como agentes sociales de transformación en procesos de prevención ante la violencia, en procura de promover relaciones sociales simétricas al interior de los medios de comunicación.
En otro ámbito, la dimensión mediática de Tecnología muestra un avance importante a nivel del conocimiento, por parte de la audiencia femenina universitaria, pero la identificación de la violencia desde un sentido crítico, implica el desarrollo de capacidades no sólo en acceso y uso de tecnología, sino en interacción, producción, difusión de contenido, ideología y valores.

Las investigaciones que consideren el desarrollo de competencias mediáticas en las audiencias, para identificación y prevención de la violencia de género en medios masivos audiovisuales, aun requieren mayor profundidad, sobre todo para orientar acciones hacia el empoderamiento de las mujeres.

Estudios descriptivos como el Monitoreo Global de Medios aportan en la caracterización de los contenidos de noticias televisivas que, vinculados al conocimiento de las competencias mediáticas de las audiencias permitirán establecer acciones estratégicas de prevención ante la violencia, considerando que "el tratamiento mediático de las desigualdades de género es sólo una extensión de la posición que tienen que enfrentar las mujeres en la sociedad" (Alfaro, 2007, p. 129).

\section{CONCLUSIONES}

El estudio cumplió el objetivo de determinar la representación de las mujeres, dentro las noticias sobre violencia de género difundidas, a través de dos canales privados (Red Unitel y Red UNO) y uno público (Bolivia TV) de alcance nacional. La representación expresa relaciones de poder, donde las mujeres se encuentran en desigualdad. Esta representación se caracteriza por la reproducción de prejuicios y estereotipos relacionados con lo doméstico y sumiso. A su vez la hipótesis fue probada por cuento la representación de las mujeres es sexista y desde los roles de género reproductivos

Asimismo, se ha precisado el nivel de competencia mediática de estudiantes mujeres de la Carrera de Ciencias de la Comunicación Social de la Universidad Mayor de San Andrés que observaron dichas informaciones. El nivel de competencia en general es básico. Sólo una dimensión (Tecnología) presenta un nivel avanzando. La hipótesis del estudio fue probada y resultó ser acertada porque, el nivel de competencia mediática de las estudiantes es limitado, frente a las noticias sobre violencia de género. Por tanto, será necesario profundizar en el desarrollo de capacidades orientadas a fortalecer conocimientos, actitudes y prácticas que permitan el reconocimiento de patrones de violencia de género visibles en contenidos informativos difundidos por televisión, desde una comprensión crítica, autónoma y reflexiva. 
A su vez, la presencia de mujeres protagonistas de las informaciones donde existe violencia de género, visibiliza la necesidad de trabajar la noticia desde un sentido preventivo y no desde el morbo o la espectacularización. Este punto guarda relación directa con la dimensión mediática de Ideología y Valores, que aporta en la identificación de estereotipos de género, desde el desarrollo de la comprensión crítica frente a las informaciones. Esta dimensión en el estudio, presenta un nivel básico.

Las investigaciones deben profundizar en el conocimiento de los roles que desarrollan las mujeres en espacios de decisión al interior de los medios de comunicación. El Global Report on the Status of Women in the news media (2019) establece que el 23\% de los principales editores de los 200 medios, son mujeres, pero sólo el 23\% llega a cargos directivos. A su vez Galindo (2020) señala que "el tema de fondo no es la cantidad de mujeres que son parte de un medio, ni la precisión respecto a si ocupan o no cargos directivos, sino el centro es interpelar la postura de las mujeres si actúan de forma utilitaria estando en los medios".

\section{REFERENCIAS BIBLIOGRÁFICAS}

Alfaro, R. M. (2007). Medios de comunicación, género y ciudadanía. Recuperado en: www.mujeresenred.net/ spip.php?articule1406

Bolla, L., \& Gómez, N. (2017). Desanudando las tramas discursivas patriarcales: análisis de las representaciones del feminicidio y su subversión en el arte. Recuperado de http://bit.ly/2SAp3hq

Chaher, S. (2010). Violencia Mediática: Como erradicar los contenidos discriminatorios de los medios masivos de comunicación. Recuperado de https:// www.genderit.org/es/resources/violencia-medi-tica-cmo-erradicar-los-contenidos-discriminatorios-de-losmedios-masivos-de-comunicación

Coordinadora de la Mujer (2020). Cuando el hogar es el espacio más inseguro para las mujeres. Observatorio de Género. Boletín Vida Libre de Violencia. https:// bit.ly/3emKY2d

Cruz, S. (2013). Vida, Muerte y Resistencia en ciudad Juárez. Una aproximación desde la violencia, el género y la cultura. Juan Pablos Editores.

Espinosa, Y., Gómez, D., Lugones, M., y Ochoa, K. (2013). Reflexiones pedagógicas en torno al feminismo decolonial. Una conversación a cuatro voces. En: W. Catherine, (Ed.), Pedagogías Decoloniales Prácticas insurgentes de resistir, (re) existir, y (re) vivir, 403-443. Abya Yala.
Fedorov, A. \& Levitskaya, A. (2015). Situación de la educación en medios y la competencia crítica en el mundo actual: opinión de expertos internacionales. Comunicar, 45(23): 107-116. doi: http://dx.doi. org/10.3916/C45-2015-11

Ferrés, J., \& Piscitelli, A. (2012). Media competence. articulated proposal of dimensions and indicators. Comunicar, 19(38): 75-81. doi:10.3916/C38-2012-02-08

Galindo, M. (2020). (19 de diciembre de 2020). Entrevista [registro de audio]. María Galindo, activista feminista Mujeres Creando. La Paz.

Global Report on the Status of Women in the news media (2019) Recuperado de: https://reutersinstitute. politics.ox.ac.uk/women-and-leadership-news-media2020-evidence-ten-markets

Gutiérrez, A. \& Tyner, K. (2012). Educación para los medios, alfabetización mediática y competencia digital. Comunicar, 19(38): 31-39. doi: https://doi. org710.3916/C38-2012-02-03.

Hobbs, R. (1998). The seven great debates in the media literacy movement. Journal of Communication, 48(1): 16-32. https://doi.org/10.1111/j.1460-2466.1998. tb02734.x

Inostroza, V. N. (2009). Los asesinatos contra mujeres según TVN: Relatos televisivos que normalizan, invisibilizan y reproducen la violencia contra las mujeres. Red Chilena contra la Violencia Doméstica y Sexual, 106-114.

Koltay, T. (2011). The media and the literacies: media literacy, information literacy, digital literacy. Media, Culture \& Society, 33(2): 211-221. https://doi. org/10.1177/0163443710393382

La Razón (Ed.) (2019). Bolivia ocupa el primer lugar en violencia en Latinoamérica y el primer lugar en feminicidios en Sudamérica. (29 de mayo 2019). Recuperado de http://www.la-razon.com/ciudades/seguridad_ciudadana/Bolivia-primero-violencia-generofeminicidios_0_3156284343.html

Lagarde, M. (2011). El derecho humano de las mujeres a una vida libre de violencia. Programa Mujeres y Derechos Humanos. Recuperado de http://www. mujeresenred.net/spip.php?auteur457

Lee, A., Lau, J., Carbo, T. \& Gendina, N. (2013). Conceptual relationship of information literacy and media literacy in knowledge societies.París: UNESCO.

Livingstone, S. (2004). Media literacy and the challenge of new information and communication technologies. The Communication Review, 7(1): 3-14. http:// doi.org/db96bn

Lugones, M. (2007). Heterosexualism and the Colonial/ Modern Gender System. Hypatia, 22(1): 186 - 219. https://doi.org/10.1111/j.1527-2001.2007.tb01156.x. 
Luke, C. (2007). As seen on TV or was that my phone? New media literacy. Policy Futures in Education, 5(1): 50-58. http://doi.org/cczb2k

Ministerio de Desarrollo Social (2012). Articulado Convención Interamericana de Belém do Pará Para Prevenir, Sancionar y Erradicar la Violencia Contra la Mujer. Instituto Nacional de las Mujeres. Recuperado: http://www.inmujeres.gub.uy/innovaportal/file/19705/1/3_articulado_belem_do_para.pdf Naciones Unidas (1996). Informe de la Cuarta Conferencia Mundial sobre la Mujer. Beijín, 4 al 15 de septiembre de 1995. Recuperado del sitio: https://www. un.org/womenwatch/daw/beijing/pdf/Beijing\%20 full\%20report\%20S.pdf

Pérez-Rodríguez, M. A., Delgado, A. García-Ruiz, R. y Caldeiro, Ma. C. (2015). Niños y jóvenes antes las redes y pantallas. La educación en competencia mediática. Gedisa.

Pech, C. (2013). Mediatización/contramediatización de la violencia de género. En S. Cruz (Comp.), Vida, muerte y resistencia en ciudad Juárez. Una aproximación desde la violencia, el género y la cultura. Juan Pablos Editores.

Romero-Rodríguez, L. M., Torres-Toukoumidis, A., Pérez-Rodríguez, A., \& Aguaded, I. (2016). Analfanauts and Fourth Screen: Lack of Infodiets and Media and Information Literacy in Latin American University Students. Journal of Communication, 12: 11-25. http://dx.doi.org/10.14201/fjc2016121125

Sentamans, T. (2012). Género, violencia simbólica y medios de comunicación. Arte y políticas de identidad. Recuperado en: http://revistas.um.es/api/article/view/163021

Segato, R. (2011). Género y colonialidad: en busca de claves de lectura y de un vocabulario estratégico descolonial. En K. Bidesca y V. Vasquez (Comp.), Feminismos y Poscolonialidad. Descolonizando el feminismo desde y en América Latina. Godot.

Selva, M. (2020). Reuters Institute. https://reutersinstitute. politics.ox.ac.uk/women-and-leadership-news-media2020-evidence-ten-markets

Valdez-López, O. (2020). Telebasura, tabloidización y espectacularización. Impacto en la audiencia sur-andina y competencias mediáticas para la ciudadanía boliviana. (Tesis doctoral). Recuperada de http://rabida.uhu.es

Vega, A. (2010). La responsabilidad de la televisión mexicana en la erradicación de la violencia de género contra las mujeres y las niñas: apuntes de una investigación diagnóstica. Comunicación y Sociedad, (13): 43-68. Recuperado de http://bit.ly/2tmPms7

Vega, A. (2014). El tratamiento de la violencia contra las mujeres en los medios de comunicación. Revista Comunicación y Medios, 30: 9-25. 